\title{
Smart temperature-controlled water vapor permeable polyurethane film
}

\author{
Chia-Yen Lin ${ }^{\text {a }}$, Ken-Hsuan Liao ${ }^{\text {a }}$, Cheng-Feng Su ${ }^{\text {a }}$, \\ Chao-Hui Kuo ${ }^{\text {a }}$, Kuo-Huang Hsieh ${ }^{\text {a,b,* }}$ \\ a Institute of Polymer Science and Engineering, National Taiwan University, Taipei, Taiwan 106, Taiwan \\ ${ }^{\mathrm{b}}$ Department of Chemical Engineering, National Taiwan University, Taipei, Taiwan 106, Taiwan \\ Received 21 December 2006; received in revised form 13 April 2007; accepted 23 April 2007 \\ Available online 4 May 2007
}

\begin{abstract}
Aim of this study was to develop a temperature-controlled polyurethane (PU) film for the application in film coated clothes. The PU film should be a smart one that can control its water vapor permeability (WVP) through temperature change. The study was carried out by increasing the water vapor permeability of various breathable/waterproof PU films through variations of their hard-to-soft-segment ratio, PEG content, and isocyanate index; the thermal properties and morphologies were investigated using Fourier transform infrared (FTIR) spectroscopy, differential scanning calorimetry (DSC), and scanning electron microscopy (SEM). It was found that the WVP of the PU film (MDI/PEG/PBA/1,4-BD = 3:0.6:0.4:2) can control its WVP by temperature change by itself. The WVP of the PU film started to rise obviously at $18^{\circ} \mathrm{C}$ which is near the material's glass transition temperature $\left(23.88^{\circ} \mathrm{C}\right)$. The result also showed that the PEG content affected the WVP dramatically; higher water permeabilities occurred at higher percentages of PEG in the main chain, but with concomitant decreases in the mechanical strengths. The most permeable PU film had a WVP of $6745 \mathrm{~g} / \mathrm{m}^{2} /$ day, a tensile strength of $29.38 \mathrm{MPa}$, and a tear strength of $112 \mathrm{~kg} / \mathrm{cm}$.
\end{abstract}

(C) 2007 Elsevier B.V. All rights reserved.

Keywords: PU film; Breathable/waterproof; WVP; PEG

\section{Introduction}

Research on water vapor permeability of polyurethane (PU) film was carried out over different formulation sets by varying hard segment concentrations, isocyanate indexes, and different ratios of PEG/PBA. Also, polyurethane film water vapor permeability near $T_{\mathrm{g}}$ at different humidity is studied in this paper.

PU comprises a class of materials whose properties vary widely: from rubbery to glassy, and from linear thermoplastic polymers to thermosetting polymers. This versatility can be exploited in conjunction with various processing and composition techniques to fulfill a vast variety of product requirements [1-3]. If the component compounds contain isocyanate groups or active hydrogen atoms (e.g., polyethers or polyesters), the processing conditions can be tailored to produce PU molecular structures that have desirable physical properties [4]. The PU main chain includes both soft (with low glass transition temper-

\footnotetext{
* Corresponding author. Tel.: +886 2 33665314; fax: +8862 33665314 . E-mail address: khhsieh@ntu.edu.tw (K.-H. Hsieh).
}

ature $\left.\left(T_{\mathrm{g}}\right)\right)$ and rigid segments. The soft segments, which arise from high-molecular-weight polyols, provide rubbery properties. The hard segments, which provide crosslinking agents and crystalline chains for PU, are composed of isocyanate and low-molecular-weight diols [5]. Kim and Kim [6] found that the mechanical properties of PU were enhanced at higher polyester-type polyol (PTAd) contents, prepared using IPDI and PTAd/PPG as the hard and soft segments, respectively [7]. Xiu et al. [8], who utilized ester-type PTAd and ether-type PPG as polyols to synthesize PU, discovered that better mechanical properties arose from the ester-type polyol PU. Yen and Kuo [9] studied the effects of various kinds of soft segments (PCL, PEG, PCL/PEG blending, and triblock PCL-PEG-PCL) on the properties of $\mathrm{PU}$; the best properties were observed for the single ester-type PU, followed by PCL-PEG-PCL PU, as a result of conformational and the inter-molecule hydrogen bonding phenomena [10]. Among these systems, the ester-ether PU exhibits the highest water vapor permeability (WVP). Because of macro phase separation among the soft segments of the PU, higher water vapor permeability is obtained at higher PEG contents. Yen and Kuo [11] also modified the soft segment composition 
of PCL-PEG-PCL triblock PU polyol and found that a higher WVP, lower mechanical properties, and obvious macro phase separation could be obtained upon increasing the EG ratio in the soft segment [12]. Yen and Kuo [13] discovered that irrespective of the nature of the PCL-PEG-PCL triblock or of the blending of the PCL/PEG soft segments, the mechanical properties increased upon increasing the NCO-to-OH ratio. The WVP increases at higher percentages of 2,2-bis(hydroxyl methyl) propionic acid (DMPA) and greater NCO-to-OH ratios. In terms of the thermal properties, the value of $T_{\mathrm{g}}$ increases upon increasing the NCO-to-OH ratio. Jeong et al. [14] discovered that the PEG and DMPA forms of PU have lower mechanical properties, and higher values of WVP can be obtained from lower values of $T_{\mathrm{g}}$. Cho et al. [15] found that the WVP decreased upon increasing the percentage of the PU hard segment or by using a concentrated PU solution.

The specific focus of this study was to determine the water vapor permeability near the values of $T_{\mathrm{g}}$, using the PEG/PBA blended polyols as soft segments of the polyurethane film. Herein, we also discuss the mechanical strength and tear strength of the resulting PU films.

\section{Experimental}

\subsection{Chemicals}

4,4-Diphenylmethane diisocyanate (MDI; TCI Chem. Co.), ethanol (99.5\%; Acros Co.), 1,4-butanediol (1,4-BD, >99\%; Acros Co.), and N,N-dimethylformamide (DMF; Acros Co.) were used as received. Polybutyleneadipate (PBA, M.W. 700) was supplied by U-Conn Technology, Taiwan. Poly(ethylene oxide glycol) (PEG) samples (M.W. 600 and 2000) were supplied by Sino Chem., Japan. The PBA and PEG samples were degassed at $60^{\circ} \mathrm{C}$ under vacuum overnight prior to use.

\subsection{Preparation of polyurethane films}

$\mathrm{MDI} /$ polyol samples, dissolved in DMF at various mixing ratios $(2: 1,3: 1,4: 1)$, were placed in four-neck reactors and stirred at $5 \mathrm{~Hz}(300 \mathrm{rpm})$ and $70^{\circ} \mathrm{C}$. The changes in the appearance of the signal for the isocyanate (NCO) group $\left(2270 \mathrm{~cm}^{-1}\right)$ were monitored using FTIR spectroscopy.

The PU solution was poured onto a mold having a Teflon coating; the thickness was controlled to within $0.01-0.05 \mathrm{~mm}$. The sample was then placed in a hood for $48 \mathrm{~h}$ to remove the DMF solvent, resulting in a PU film.

\subsection{Testing methods}

The water vapor permeability experiment is carried out according to JIS-1099 A1 method, which an upright cup covered with the polyurethane sample film and filled with fixed amount of calcium chloride inside, is placed in a controlled chamber at fixed temperatures and humidity at 90\%. WVP values were calculated by the gained weight of desiccant and divided by the fixed surface area of the polyurethane film and the time inside the controlled chamber. The mechanical

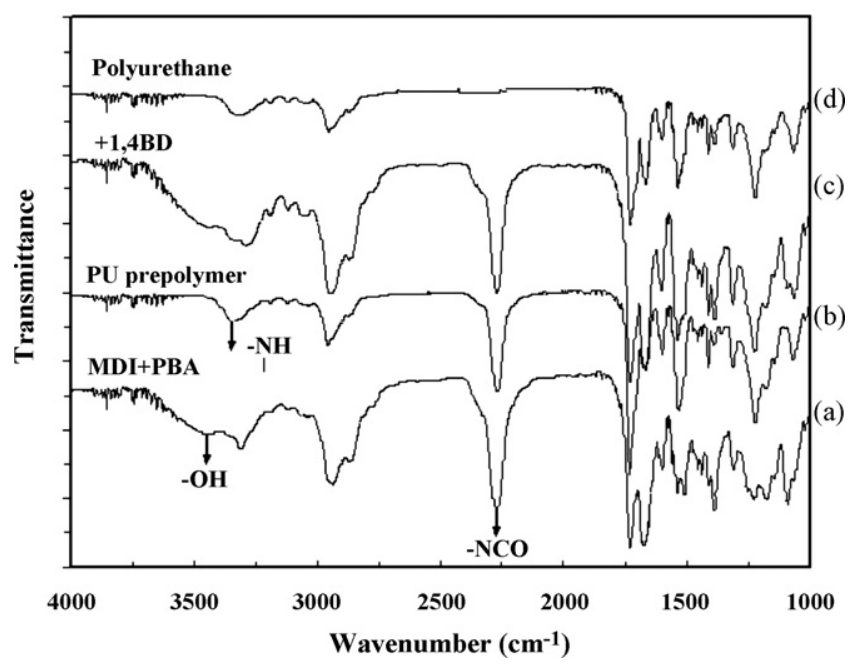

Fig. 1. FTIR spectra recorded at four reaction states: (a) 2MDI + PBA; (b) PU prepolymer; (c) PU prepolymer +1, 4BD; (d) polyurethane.

properties were measured according to ASTM D412 (tensile strength) and ASTM 62C (tear strength). The thermal properties were measured using differential scanning calorimetry (DSC, Mettler-Toledo DSC-821 ${ }^{\mathrm{e}}$, USA). A heating rate of $10{ }^{\circ} \mathrm{C} / \mathrm{min}$ was employed over the temperature range from -60 to $+200^{\circ} \mathrm{C}$.

\section{Results and discussion}

\subsection{Reaction}

The FTIR spectra in Fig. 1(a) indicate that the signals for the hydroxyl $\left(\mathrm{OH}, 3400 \mathrm{~cm}^{-1}\right)$ and $\mathrm{NCO}\left(2270 \mathrm{~cm}^{-1}\right)$ groups coexisted in the initial reaction state. In the intermediate state (Fig. 1(b)), the signal for the $\mathrm{OH}$ groups disappeared, that of the NCO groups reduced to half of its original intensity, and a signal for NH units appeared at $3300 \mathrm{~cm}^{-1}$, suggesting that the PU prepolymer had been formed. In the final step, the chain extender (1,4-BD) was added; Fig. 1(c) indicates that the peak intensity of the residual NCO units $\left(2270 \mathrm{~cm}^{-1}\right)$ eventually disappeared. The changes in the intensity of the signal of the carbonyl groups $\left(\mathrm{C}=\mathrm{O}\right.$ ) of urethane linkages (at $1740 \mathrm{~cm}^{-1}$ ) indicate the chemical reactions of the diisocyanate and the polyol and of the diisocyanate and 1,4-BD.

\subsection{Thermal properties}

Table 1 presents the thermal properties of various samples. The value of $T_{\mathrm{g}}$ increased upon increasing the content of the hard segment in the PU, presumably because of the rigidity resulting from the larger number of aromatic rings in the TPU main chain and the greater number of hydrogen bonds formed between $\mathrm{NH}$ and $\mathrm{C}=\mathrm{O}$ groups.

In Table 1, we observe that increasing the soft segment ratio, which enhanced the flexibility of the PU chains, also decreased the value of $T_{\mathrm{g}}$. These results are consistent with those described previously. 
Table 1

Designation and thermal properties of PU samples at various sample ratios

\begin{tabular}{lllr}
\hline MDI/PEG/PBA/1,4-BD & Designation & Isocyanate index & $T_{\mathrm{g}}\left({ }^{\circ} \mathrm{C}\right)$ \\
\hline $2 / 0.4 / 0.6 / 1$ & PU1 & 1.00 & -9.96 \\
$3 / 0.4 / 0.6 / 2$ & PU2 & 1.00 & 12.86 \\
$4 / 0.4 / 0.6 / 3$ & PU3 & 1.00 & 28.03 \\
$4 / 0.6 / 0.4 / 3$ & PU4 & 1.00 & 26.35 \\
$4 / 0.8 / 0.2 / 3$ & PU5 & 1.00 & 13.38 \\
$4 / 1 / 0 / / 3$ & PU6 & 1.00 & 10.21 \\
$3 / 0.6 / 0.4 / 2$ & PU7 & 1.00 & 6.09 \\
$3 / 0.6 / 0.4 / 2$ & PU8 & 1.10 & 13.37 \\
$3 / 0.6 / 0.4 / 2$ & PU9 & 1.20 & 23.88 \\
\hline
\end{tabular}

\subsection{Mechanical properties}

Fig. 2 displays the tensile strengths and tear strengths for polymers at various hard/soft segment ratios. The mechanical strength and the tear strength both increased with increasing hard segment content in the PU chain, presumably because of the increased rigidity and strength resulting from the hydrogen bonds formed between the $\mathrm{NH}$ and $\mathrm{C}=\mathrm{O}$ groups.

Fig. 3 displays the tensile strengths and tear strengths for samples containing various PEG contents in the polyol, but at the same hard/soft segment ratio. Both the tensile strength and the tear strength decreased upon increasing the soft segment PEG/PBA ratio. The higher flexibility of the PEG units relative to that of PBA meant that it could diffuse more readily into the hard segments and reduce the crystallinity. In addition, the ester-type PBA presents carbonyl groups along the PU main chain, which readily interact with the hard segments.

Fig. 4 presents the tensile strengths and tear strengths as a function of various isocyanate indexes. Both the tensile strength and the tear strength increased upon increasing the isocyanate index because of the increasing number of hard segments. Furthermore, the presence of too many hard segments, which enhance the phase separation domains dispersed into PU molecule, will also increase the mechanical properties.

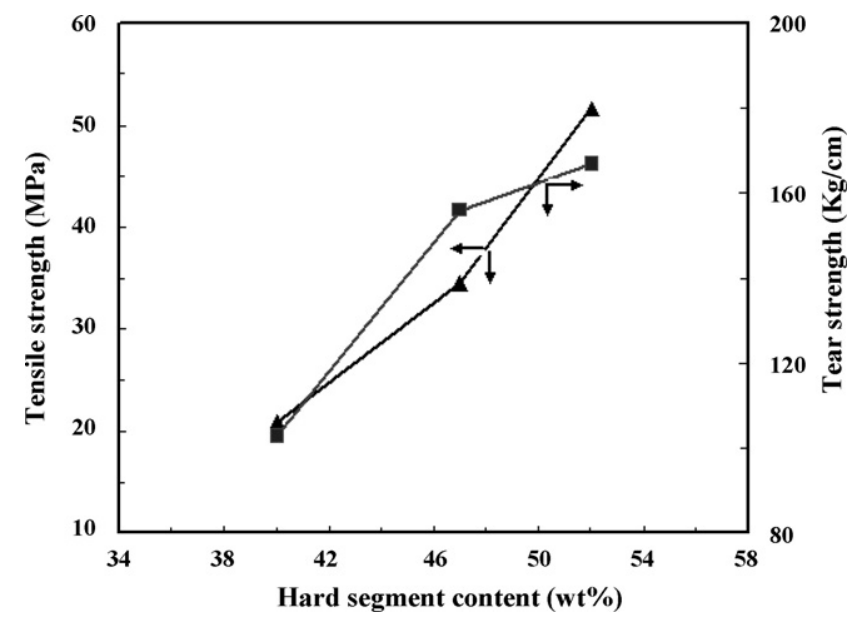

Fig. 2. Tensile strength and tear strength plotted as functions of the hard/soft segment ratio of the PUs.

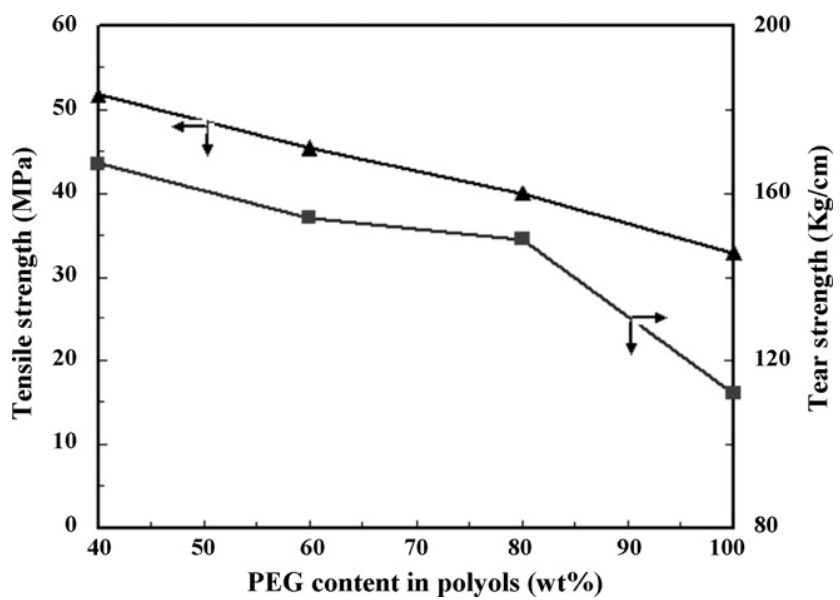

Fig. 3. Tensile strength and tear strength plotted as functions of the PEG content in the polyols at a constant MDI/polyol/1,4-BD) molar ratio (4:1:3).

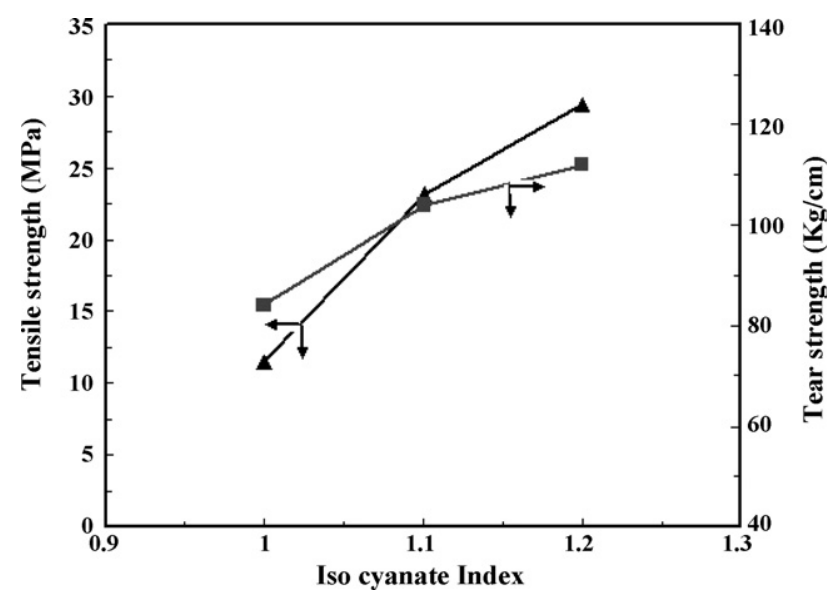

Fig. 4. Tensile strength and tear strength plotted as functions of the isocyanate index of PU at an MDI/polyol/1,4-BD molar ratio of 3:1:2.

\subsection{Water vapor permeability}

Table 2 presents the results of WVP analyses of various samples. The WVP decreased with increasing hard segments along the PU chain, comparing PU1, PU2, PU3, presumably more rigid hard segments surround the soft segments prohibiting water permeation [16,17]. In Table 2, comparing PU3, PU4, PU5, PU6,

Table 2

Mechanical properties and WVP of PU samples at various sample ratios

\begin{tabular}{lllc}
\hline Samples & \multicolumn{2}{l}{ Mechanical properties } & WVP $\left(\mathrm{g} / \mathrm{m}^{2}\right.$ day $)$ \\
\cline { 2 - 3 } & $\begin{array}{l}\text { Tensile strength } \\
(\mathrm{MPa})\end{array}$ & $\begin{array}{l}\text { Tear strength } \\
(\mathrm{kg} / \mathrm{cm})\end{array}$ & \\
\hline PU1 & 20.92 & 103 & 1257 \\
PU2 & 34.53 & 156 & 984 \\
PU3 & 51.65 & 167 & 813 \\
PU4 & 45.37 & 154 & 1742 \\
PU5 & 39.84 & 149 & 4648 \\
PU6 & 32.90 & 121 & 10729 \\
PU7 & 11.47 & 84 & 2484 \\
PU8 & 23.17 & 104 & 3744 \\
PU9 & 29.38 & 112 & 6745 \\
\hline
\end{tabular}




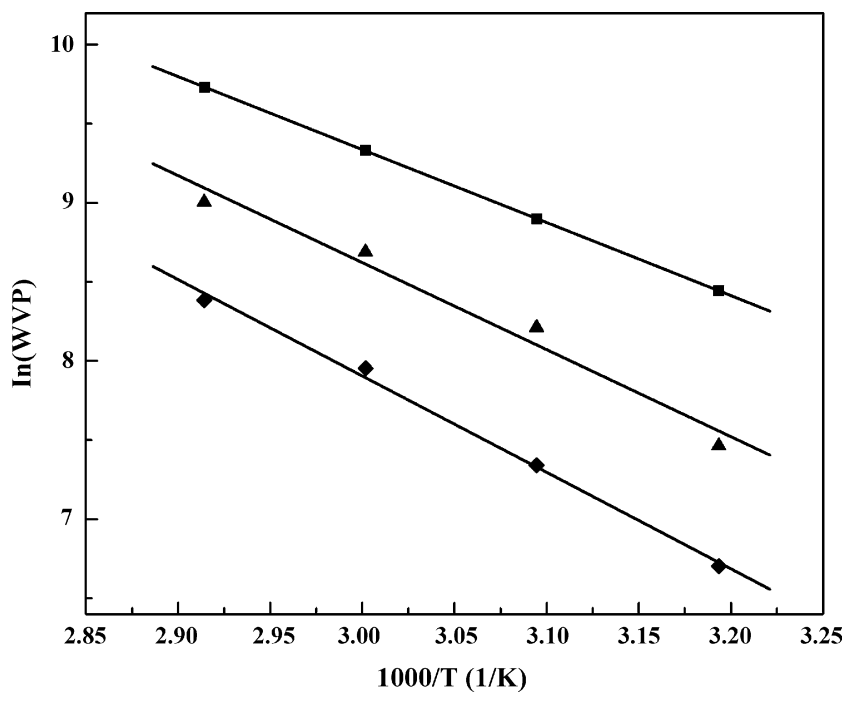

Fig. 5. Natural log of water vapor permeability plotted as a function of inverse temperature and the PEG content in the polyol at an MDI/polyol/1,4-BD molar

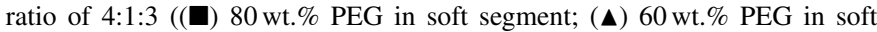
segment; ( $40 \mathrm{wt}$ \% PEG in soft segment).

we observe that the WVP also increased greatly upon increasing the PEG/PBA ratio of the soft segments. In comparison with PBA, PEG is more hydrophilic, water soluble, and flexible.

Although, in theory, the WVP should decrease upon increasing the isocyanate index, in Table 2, comparing PU7, PU8, PU9, we observe the opposite behavior, presumably because of the many well-dispersed small domains within the PU microstructure that arose through hydrogen bond formation between the $\mathrm{NH}$ and $\mathrm{C}=\mathrm{O}$ groups.

Temperature dependence of gas permeability coefficient in polymer can be described by Arrhenius type equation [18]:

$P=P_{0} \exp \left(\frac{-E \pi}{P T}\right)$

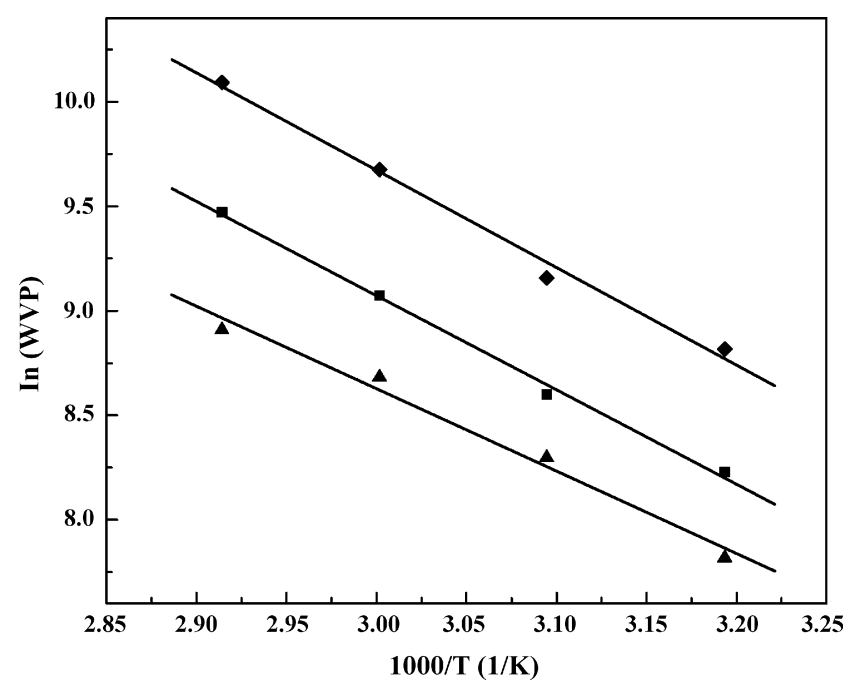

Fig. 6. Natural log of water vapor permeability plotted as a function of inverse temperature and the isocyanate index at an MDI/polyol/1,4-BD molar ratio of 3:1:2 (( $\mathbf{\Delta})$ isocyanate index $=1$; $(\boldsymbol{\square})$ isocyanate index $=1.1 ;(\checkmark)$ isocyanate index $=1.2$ ).

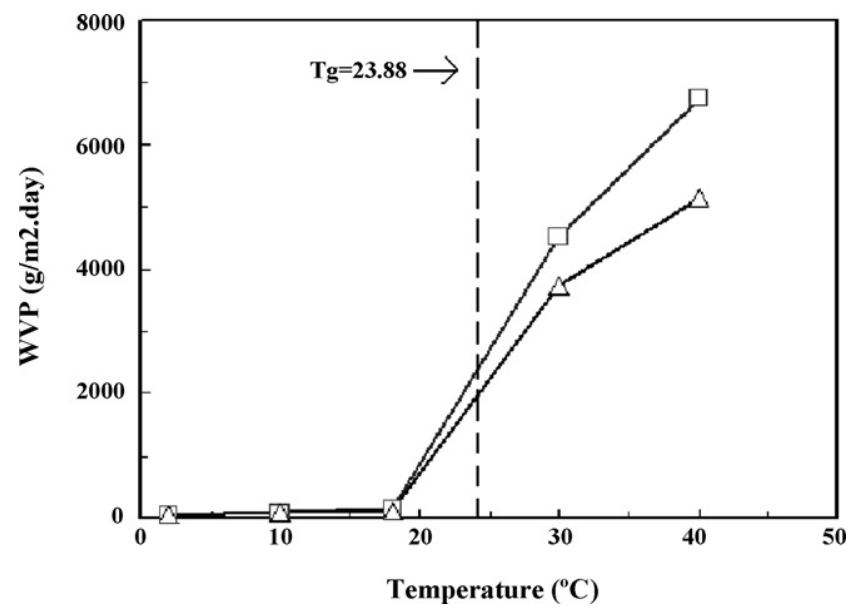

Fig. 7. Water vapor permeabilities of PU specimens (MDI/PEG/PBA/1,4 $\mathrm{BD}=3: 0.6: 0.4: 2)$ plotted as a function of the temperature and the relative humidity $((\square) \mathrm{RH}=90 ;(\triangle) \mathrm{RH}=70)$.

where $P_{0}$ is the pre-exponential factor and $E_{\mathrm{p}}$ is the apparent activation energy of permeation. From the equation above, it is know that $\ln (\mathrm{WVP})$ and $(1 / T)$ is linear relation. In Figs. 5 and 6, we mention that obvious variations in the WVP were obtained at different temperatures. It is observed that the relationship between the natural log WVP and the inverse absolute temperature is linear dependence. Indeed, a higher temperature causes the soft segments to become more flexible such that the water vapor molecule can pass through more readily.

\subsection{Water vapor permeability analysis near the glass transition temperature}

Fig. 7 indicates that the WVP of the PU film (MDI/PEG/PBA/1,4-BD = 3:0.6:0.4:2) is affected dramatically by temperature changes near to the material's value of $T_{\mathrm{g}}$ (ca. $23.88^{\circ} \mathrm{C}$ ). The result showed that the PU film can control the

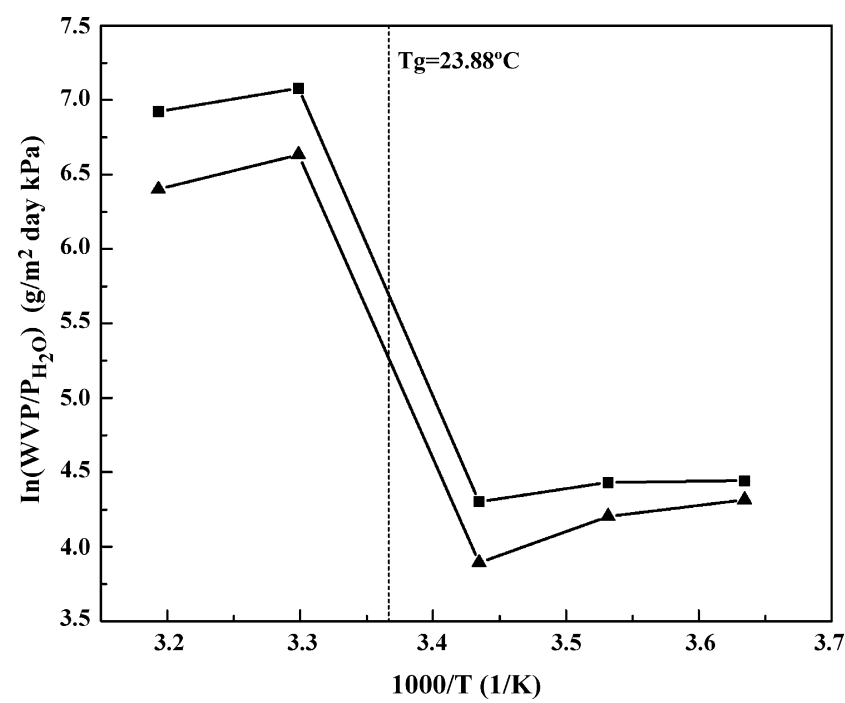

Fig. 8. Natural $\log$ of (water vapor permeability divided by partial water pressure) plotted as function of inverse temperature of (MDI/PEG/PBA/1,4$\mathrm{BD}=3$ :0.6:0.4:2) and the relative humidity $((\mathbf{\square}) \mathrm{RH}=90 ;(\boldsymbol{\Lambda}) \mathrm{RH}=70)$. 


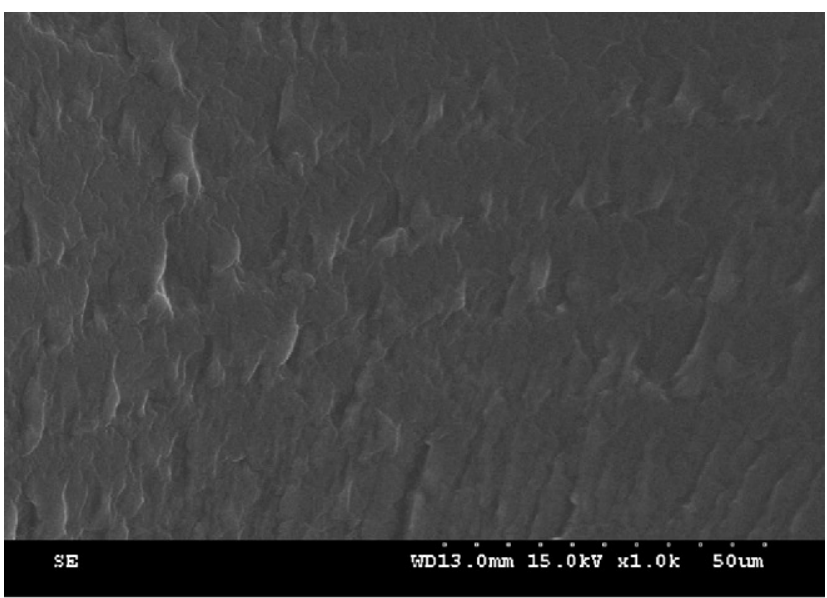

(a)

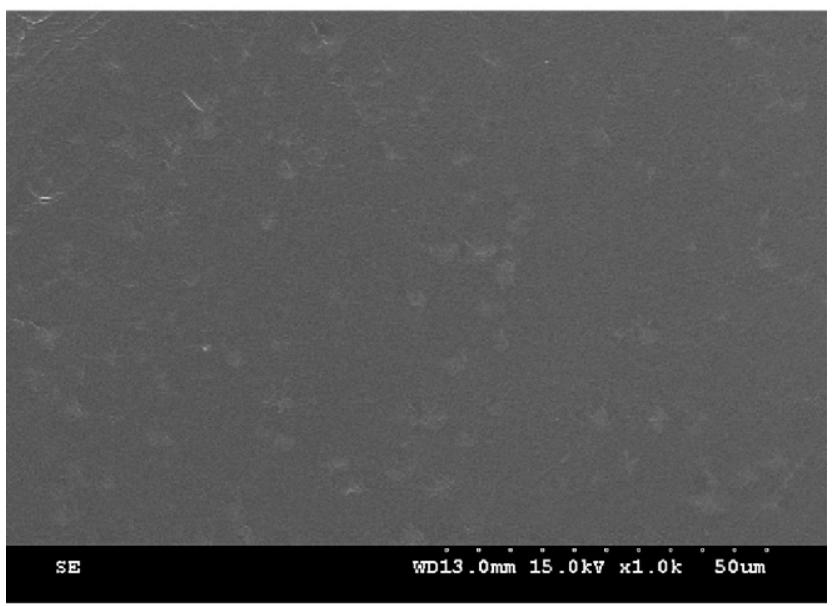

(b)

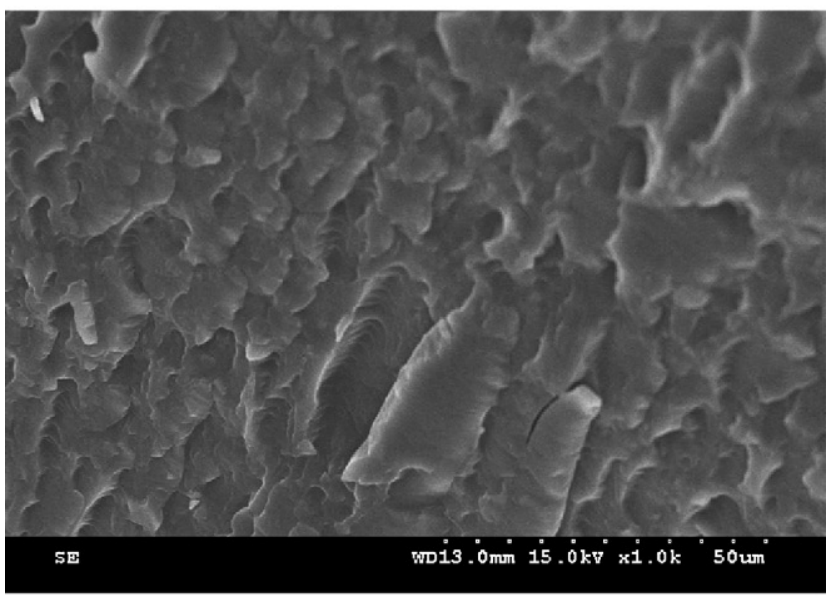

(c)

Fig. 9. Morphologies of PU samples at various MDI/PEG/PBA/1,4-BD ratios. (a) PU(MDI/PEG/PBA/1,4-BD = 2:0.4:0.6:1), (b) PU(MDI/PEG/PBA/1,4$\mathrm{BD}=3: 0.4: 0.6: 2)$ and (c) $\mathrm{PU}(\mathrm{MDI} / \mathrm{PEG} / \mathrm{PBA} / 1,4-\mathrm{BD}=4: 0.4: 0.6: 3)$.

WVP which stays low until the temperature is higher than $18^{\circ} \mathrm{C}$ and starts to rise dramatically. In order to ignore the affection from the water partial pressure driving force which is changing exponentially with temperature in a similar manner to the WVP, the WVP was divided by the water partial pressure driving force and plotted as log-plot versus inverse temperature in Fig. 8. From Fig. 8, it is also observed that $\mathrm{WVP} / P_{\mathrm{H}_{2} \mathrm{O}}$ still rises dramatically at temperature near materials' $T_{\mathrm{g}}$.

At temperatures below $T_{\mathrm{g}}$, the PU film exists in a glassy state that is very rigid. The WVP of PU film is provided by the noncrystalline part, which exists in a rubber-like state; this phase can move when the temperature is between the glass transition temperature and the crystalline temperature. Therefore, the WVP is low when the temperature is below the $T_{\mathrm{g}}$, but it increases when the temperature is above the $T_{\mathrm{g}}$.

\subsection{Cross-sectional surface morphologies}

Fig. 9 displays the different morphologies observed at various percentages of hard segments in the PU. An excess of hard segments caused more wrinkles to appear on the PU film surface; these wrinkles arose through micro phase separation of the hard and soft segments.

\section{Conclusions}

The utilization of PEG/PBA multiple-polyol system presented better WVP than PBA system of PU films. The result showed that the WVP of the PU film (MDI/PEG/PBA/1,4$\mathrm{BD}=3: 0.6: 0.4: 2)$ stayed low until the temperature was higher than $18^{\circ} \mathrm{C}$. Then the WVP started to rise obviously. The WVP of PU films increased upon increasing the hard segment ratio, the temperature, or the isocyanate index, but it decreased when the temperature was decreased to below the $T_{\mathrm{g}}$. The glass transition temperature of PU films increased upon increasing the percentage of hard segments or decreasing the soft segment PEG/PBA ratio. The mechanical strength and the tear strength both increased upon (a) increasing the percentage of hard segment, (b) decreasing the soft segment PEG/PBA ratio, or (c) increasing the isocyanate index.

\section{Acknowledgement}

We sincerely appreciate the financial support from National Science Council of Taiwan through the Grant No. NSC92-2622E-002-014-CC3.

\section{References}

[1] K.H. Hsieh, C.C. Tsai, S.M. Tseng, Vapor and gas permeability of polyurethane membranes. Part I. Structure-property relationship, J. Membr. Sci. 49 (1990) 341.

[2] K.H. Hsieh, C.C. Tsai, D.M. Chang, Vapor and gas permeability of polyurethane membranes. Part II. Effect of functional group, J. Membr. Sci. 56 (1991) 279.

[3] Z.F. Wang, B. Wang, X.M. Ding, M. Zhang, L.M. Liu, N. Qi, J.L. Hu, Effect of temperature and structure on the free volume and water vaporpermeability in hydrophilic polyurethanes, J. Membr. Sci. 241 (2004) 355.

[4] T.T. Hsieh, K.H. Hsieh, G.P. Simon, C. Tiu, Interpenetrating polymer networks of 2-hydroxyethyl methacrylate terminated polyurethanes and polyurethanes, Polymer 40 (1999) 3153.

[5] K.S. Ho, K.H. Hsieh, S.K. Huang, T.H. Hsieh, Polyurethane-based conducting polymer blends: I. Effect of chain extender, Synth. Met. 107 (1999) 65 . 
[6] C.K. Kim, B.K. Kim, IPDI-based polyurethane ionomer dispersions: effects of ionic, nonionic hydrophilic segments, and extender on particle size and physical properties of emulsion cast film, J. Appl. Polym. Sci. 43 (1991) 2295.

[7] A.K. Mishra, D.K. Chattopadhyay, B. Sreedhar, K.V.S.N. Raju, Thermal and dynamic mechanical characterization of polyurethane-urea-imide coatings, J. Appl. Polym. Sci. 102 (2006) 3158.

[8] Y. Xiu, D. Wang, C. Hu, S. Ying, J. Li, Morphology-property relationship of segmented polyurethaneurea: influences of soft-segment structure and molecular weight, J. Appl. Polym. Sci. 48 (1993) 867.

[9] M.S. Yen, S.C. Kuo, Effects of mixing procedure on the structure and physical properties of ester-ether-type soft segment waterborne polyurethane, J. Appl. Polym. Sci. 61 (1996) 1639.

[10] C.C. Peng, V.A. Abetz, Simple pathway toward quantitative modification of polybutadiene: a new approach to thermoreversible cross-linking rubber comprising supramolecular hydrogen-bonding networks, Macromolecules 38 (2005) 5575.

[11] M.S. Yen, S.C. Kuo, PCL-PEG-PCL triblock copolydiol-based waterborne polyurethane. I. Effects of the soft-segment composition on the structure and physical properties, J. Appl. Polym. Sci. 65 (1997) 883.
[12] D.K. Chattopadhyay, B. Sreedhar, K.V.S.N. Raju, Thermal stability of chemically crosslinked moisture-cured polyurethane coatings, J. Appl. Polym. Sci. 95 (2005) 1509.

[13] M.S. Yen, S.C. Kuo, PCL-PEG-PCL triblock ester-ether copolydiolbased waterborne polyurethane. II. Effect of $\mathrm{NCO} / \mathrm{OH}$ mole ratio and DMPA content on the physical properties, J. Appl. Polym. Sci. 67 (1998) 1301.

[14] H.M. Jeong, B.K. Ahn, S.M. Cho, B.K. Kim, Water vapor permeability of shape memory polyurethane with amorphous reversible phase, J. Polym. Sci., Part B: Polym. Phys. 38 (2000) 3009.

[15] J.W. Cho, Y.C. Jung, B.C. Chun, Y.C. Chung, Water vapor permeability and mechanical properties of fabrics coated with shape-memory polyurethane, J. Appl. Polym. Sci. 92 (2004) 2812.

[16] S.L. Huang, R.C. Ruaan, J.Y. Lai, Gas permeability of cupric ion containing HTPB based polyurethane membranes, J. Membr. Sci. 123 (1997) 71.

[17] Y.G. Jeong, T. Hashida, S.L. Hsu, C.W. Paul, Factors influencing curing behavior in phase-separated structures, Macromolecules 38 (2005) 2889.

[18] Z.F. Wang, B. Wang, X.M. Ding, M. Zhang, L.M. Liu, N. Qi, J.L. Hu, Effect of temperature and structure on the free volume and water vapor permeability in hydrophilic polyurethanes, J. Membr. Sci. 241 (2004) 355. 